
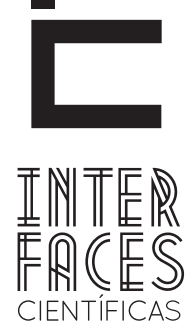

DIREITO

\title{
REPRODUCÇÃO EM PACIENTE COMATOSO MASCULINO: UM ESTUDO ACERCA DA COLISÃO ENTRE A AUTONOMIA/DIGNIDADE DO PACIENTE E A LIBERDADE REPRODUTIVA DA MULHER EM FACE DOS PRINCÍPIOS E DIREITOS FUNDAMENTAIS
}

Tiago Mafra Lima ${ }^{1}$

\section{RESUMO}

Com as transformações científicas das últimas décadas tornou-se necessário ampliar as discussões que envolvem os procedimentos e técnicas da Biomedicina e sua relação com o Direito. Tal necessidade pode ser notada diante de situações em que existem novos procedimentos e novas circunstâncias de aplicação das técnicas, como é o caso da reprodução em paciente comatoso masculino, não obstante, não haver ainda regulamentação jurídica do procedimento. Assim, o presente estudo realizará uma análise das técnicas de reprodução assistida e das circunstâncias do estado de coma irreversível em face dos princípios constitucionais da liberdade reprodutiva da mulher, da dignidade da pessoa humana e da autonomia do paciente comatoso. Esse artigo abordará possíveis soluções quanto à realização ou não do procedimento de reprodução assistida com material genético oriundo de paciente em coma. Pretende-se, portanto, demonstrar, através de uma metodologia dedutiva, a impossibilidade da reprodução assistida quando a coleta de sêmen é realizada em paciente em estado comatoso, assim como a possibilidade quando o sêmen for doado anteriormente ao estado de coma e tenha ainda o doador deixado por escrito ou comprovado ser esse o seu desejo.

\section{PALAVRAS-CHAVE}

Reprodução Assistida. Paciente Comatoso. Bioética. Direitos Fundamentais. 


\section{ABSTRACT}

With the scientific transformations of recent decades has become necessary to broaden the discussions involving the procedures and techniques of Biomedicine and your relationship with the Law. This need can be seen to cases where there are new procedures and conditions for applying the new techniques, such as in vitro fertilization in male comatose patient; however, there is no still legal regulation of the procedure. Thus, this study will conduct an analysis of assisted reproduction techniques and the circumstances of the state of irreversible coma in the face of the constitutional principles of reproductive freedom of women, human dignity and autonomy of the comatose patient. This article will address possible solutions as to whether or not the procedure of assisted reproduction with genetic material coming from comatose patient. It is intended, therefore, to demonstrate, through a deductive methodology, the impossibility of assisted reproduction when collecting semen is held in comatose patients, as well as the possibility when semen is donated before the coma and still have donor left in writing or evidenced being that is your desire.

\section{KEYWORDS}

Assisted Reproduction. Comatose Patient. Bioethics. Fundamental Rights.

\section{CONSIDERAÇ̃̃ES INICIAIS}

Os últimos séculos foram marcados por grandes transformações científicas e sociais. Neste período, mudou o mundo e a percepção humana. 0 positivismo do final do século XIX, otimista em relação ao progresso, cultuou a ciência e a industrialização, vendo na construção de novos produtos 0 caminho para o futuro. 0 século XX, existencialis-

\section{RESUMEN}

Con las transformaciones científicas de las últimas décadas ha sido necesario ampliar las discusiones que envuelven los procedimientos y técnicas de la Biomedicina y su relación con el Derecho. Tal necesidad se puede notar delante de situaciones en que existen nuevos procedimientos y nuevas circunstancias de aplicación de las técnicas, como es el caso de la reproducción en paciente masculino en coma, a pesar de no haber aún reglamentación jurídica del procedimiento. De esa forma, la presente investigación realizará un análisis de las técnicas de reproducción asistida y de las circunstancias del estado de coma irreversible delante de los principios constitucionales de la libertad reproductiva de la mujer, de la dignidad de la persona humana y de la autonomía del paciente en coma. Este artículo tratará de posibles soluciones cuanto a la realización o no del procedimiento de reproducción asistida con material genético oriundo de paciente en coma. Se pretende, por lo tanto, demostrar, a través de una metodología deductiva, la imposibilidad de la reproducción asistida cuando la colecta de semen es realizada en paciente en estado de coma, como también la posibilidad cuando el semen sea donado anteriormente al estado de coma y haya aún el donador dejado por escrito o comprobado ser ese su deseo.

\section{PALABRAS CLAVE}

Reproducción Asistida. Paciente Coma. Bioética. Derechos Fundamentales.

ta, século das grandes revoluções, trouxe consigo, novos paradigmas e colocou o ser humano "corpo e espírito" como parte e caminho do progresso. Estamos diante de transformações que atingem todos os setores da vida humana, de modo, que já não vivemos uma "época de mudanças", mas uma "mudança de época". 
É nesse novo contexto de inovações revolucionárias, no qual o corpo humano ganha importância, que a Biomedicina se insere. Todavia, juntamente com as técnicas e a ciência biomédica moderna, dúvidas e questionamentos, de natureza ético-axiológica, quanto à possibilidade de realização de determinados procedimentos médicos, como a reprodução assistida em paciente comatoso, surgem e causam angústia aos profissionais da área.

No mesmo veio, encontra-se a situação de análise dos procedimentos da área biomédica em face dos princípios da dignidade humana, autonomia do paciente e a liberdade reprodutiva. Dessa forma, apresenta-se

\section{REPRODUÇ̃̃O ASSISTIDAE COMA IRREVERSÍVEL}

As técnicas de reprodução assistida têm um papel acessório na solução dos problemas de infertilidade humana, facilitando o processo de procriação, quando outros métodos tenham sido ineficazes (BRASIL, 2012-A). Já o estado de coma indica a

\subsection{REPRODUCÃOA ASSISTIDA}

Falar em reprodução é sem dúvida abordar a mais importante e primitiva função relacionada aos seres vivos, pois é a partir dela que os seres eternizam a existência de suas espécies. No que compreende a condição humana, o processo de reprodução é sexuado, ou seja, depende da relação sexual de indivíduos de gêneros opostos. A superação dessa barreira por muito tempo preencheu o imaginário humano, no entanto, com o avanço das ciências e das técnicas essa não é mais uma conditio sine qua non, sendo hoje uma realidade e possuindo técnicas bastante difundidas.

A reprodução assistida é um recurso utilizado quando há impossibilidade de fecundação natural, que é a consequência do encontro sexual de humanos de gêneros opostos e em idade fértil, cujas condições a inerente necessidade de adequação da nova realidade biomédica, com o conjunto de direitos presentes na constituição pátria e no rol dos Direitos Humanos.

Assim, para alcançar os objetivos de adequar a nova realidade biomédica ao rol dos Direitos Constitucionais, o artigo foi dividido em: (1) fundamentação dos procedimentos pertinentes à pesquisa, Reprodução Assistida e Coma Irreversível; (2) exame dos princípios colidentes no caso em questão, ou seja, princípios da dignidade humana, autonomia do paciente e autonomia reprodutiva; (3) análise crítica da colisão dos direitos e por último a conclusão do trabalho apresentando uma alternativa ao problema.

falência dos mecanismos normais de manutenção do estado de consciência (PARANÁ, 2011). o que se fará a seguir é compreender o procedimento de reprodução assistida e o estado comatoso na sua vertente biomédica.

são as seguintes: o homem produzir nos testículos espermatozóides com capacidade de fecundar; a mulher produzir nos folículos ovarianos um óvulo maduro; haver o encontro de pelo menos um desses espermatozóides com o óvulo na tuba uterina, desencadeando os eventos que culminarão com a fusão dos pronúcleos masculino e feminino (SILVA, 2002).

Quando houver impossibilidade do método natural de fecundação a reprodução assistida ou artificial será uma alternativa. Esse modelo de procriação sem a realização do ato sexual era algo impensável há alguns séculos. Segundo Diniz (2001), define-se reprodução assistida como um conjunto de operações para unir artificialmente, os gametas femininos e masculinos, dando origem 
a um novo ser. As técnicas abrangem especialmente aquelas que manipulam isoladamente os gametas masculinos, depositando-os preparados, em algum ponto do genital feminino e, aqueles em que ovócitos e espermatozóides são assistidos laboratorialmente, sendo depois transferido para os zigotos ou pré-embriões consequentes (DANADIO; DANADIO, 1997).

Essa nova forma de reprodução não natural, segundo Samrsla et al. (2007), foi iniciada pelos estudos de Lázaro Spallanzani e deu início ao processo de fecundação artificial quando esse engravidou uma cadela após coletar o sêmen de um cachorro no final do século XVII. Esse método só veio a ser repetido em seres humanos no final do século XVIII, quando o médico John Hunter para solucionar a infertilidade de um casal, cujo marido era portador de grave hipospádia, depositou no ambiente intravaginal uma amostra seminal, sendo esse o primeiro caso comunicado de inseminação artificial (LOPES et al., 1997). No entanto, nos referidos casos, a reprodução se deu com a fecundação do óvulo dentro do corpo da fêmea. Essa fronteira corpórea só foi ultrapassada em 1978, quando na cidade de Oldham, na Inglaterra, nasceu o primeiro bebê de proveta, Louise Brown concebida pela fecundação in vitro dos gametas de seus pais legais (SAMRSLA et al., 2007).

Atualmente as técnicas mais comuns de reprodução assistida utilizadas, segundo Pessini e Barchifontaine (2000), são a inseminação artificial (AI) e a fertilização in vitro (FIV). A primeira é uma técnica de reprodução assistida relativamente simples e bastante antiga, consistindo na introdução do esperma na vagina, por meio de uma cânula (HRYNIEWICZ; SAUWEN, 2008). Segundo Pessini e Barchifontaine

\subsection{MORTE ENCEFÁLICA E ESTADO DE COMA IRREVERSÍVEL}

A consciência resulta de um conjugado de funções do encéfalo que permitem ao sujeito reagir à
(2000) a inseminação artificial se dá por uma transferência mecânica de espermatozóides, já previamente recolhidos e tratados, inseridos no interior do aparelho genital feminino.

Já a fertilização in vitro é uma técnica relativamente jovem, porém mais complexa. O êxito dessa técnica só foi possível a partir do melhoramento da técnica anterior e, sobretudo com a possibilidade de congelamento do sêmen, o que permitiu um espaço maior de tempo entre a doação e a fecundação. A técnica in vitro consiste em permitir o encontro do óvulo com o espermatozóide fora do organismo da mulher, numa placa de cultura ou num tubo de ensaio (SILVA, 2002). Em linhas gerais, esse método de fertilização consiste em retirar, por laparoscopia, um ou vários óvulos da mulher doadora. A produção desses óvulos é geralmente provocada por estimulação hormonal, sendo em seguida colocados em meio nutritivo. Na sequência do procedimento, aos óvulos reúne-se o esperma, havendo a fecundação. Após horas ou até dois dias, o óvulo é colocado no útero da mulher, sendo que se houver a nidificação (adesão ao útero), a gravidez segue seu ritmo natural (HRYNIEWICZ; SAUWEN, 2008). Existem ainda outras técnicas de reprodução assistida, mas todas aperfeiçoadas a partir da técnica in vitro.

O que é importante ressaltar e, sobretudo para os objetivos desse estudo, é que com a técnica in vitro, não há necessidade da existência de um imperativo temporal entre o momento da doação dos gametas masculinos e femininos, uma vez que podem ser retirados mesmo estando o doador em coma. Permite, pois, essa técnica ser realizada sem a anuência de um dos doadores, e no caso desse trabalho, do doador comatoso, que se encontra em estado não consciente.

excitação do ambiente externo e interagir com esse. Em contrapartida, o estado de coma é uma síndrome 
qualificada por um conjunto de sinais e sintomas, que pode ter várias etiologias (causas), representado por manifestações clínicas importantes que indicam a falência dos mecanismos normais de manutenção do estado de consciência (PARANÁ, 2011). Segundo Rosenberg (2009), o coma se refere ao estado clínico em que o paciente não responde a estímulos, sendo que esse estado pode ser causado por lesões estruturais no tronco cerebral, tálamo, ou hemisférios cerebrais e por anomalias metabólicas.

A Medicina segundo Muniz et al (1997) utiliza duas escalas para avaliação dos níveis de consciência: a Escala de Coma de Glasgow (ECGL) e o Estado de Coma de Jouvet (ECJ), classificando a magnitude, seriedade e o prognóstico do coma. "Quanto maior for o déficit motor, sensitivo, do tônus, dos reflexos, do nível de consciência e outras manifestações neurológicas, maior a gravidade prognóstica" (PARANÁ, 2011).

Para nosso estudo, trataremos somente do diagnóstico de morte encefálica e do coma irreversível, pertinentes ao que se pretende.

O diagnóstico clínico quanto à morte encefálica (ME) tem apoio em três bases fundamentais: coma irreversível, reflexos do tronco cerebral e ausência de apnéia (JAMA, 1968). A morte encefálica ocorre gerando danos irreversíveis, a partir da total abolição das funções cerebrais, incluindo o tronco cerebral, no qual o corpo é incapaz de manter a homeostase interna (equilíbrio do meio interno em relação ao externo), causando a destruição das células (WIJDICKS, 2001). Neste mesmo diapasão, é o entendimento do ConseIho Regional de Medicina do Estado do Paraná em seu Parecer n 1243/00:

Neste estado, o paciente não tem mais nenhuma atividade cerebral (encefálica) e o seu diagnóstico traduz uma condição irreversível, [...] o paciente está cientificamente e irreversivelmente morto, porque mesmo que se utilize de todas as terapêuticas e procedimentos possíveis, ele terminará em parada cardíaca (PARANÁ, 2011 p.2).
Como se observa, para a decretação da morte encefálica, será necessária a caracterização da ausência definitiva de função no encéfalo, persistindo porém, o funcionamento de alguns órgãos de forma espontânea ou com auxílio de aparelhos. Não obstante, deixa de existir a pessoa, passando a existir somente um cadáver, pois nada pode impedir que esse venha a falecer.

Por outro lado, o coma irreversível ou EVP (estado vegetativo persistente) deve ser diferenciado da morte encefálica, pois segundo Rosenberg (2009) é uma síndrome com várias causas em que o paciente sofre danos cerebrais graves, e o coma avançou para um estado de vigília, sem consciência detectável.

No mesmo entendimento o Conselho Regional de Medicina do Estado do Paraná no Parecer 1243/00 define:

\begin{abstract}
Nas situações de coma irreversível ou EVP existe ainda algum grau de funcionamento do tronco cerebral, com uma lesão severa e difusa dos hemisférios cerebrais. Nesta situação o paciente deixa de ter vida voluntária, mantendo-se as funções básicas do organismo, tais como, ciclo de sono e vigília e reatividade a estímulos. Esta situação difere da ME, pois no EVP existe ainda vida na pessoa acometida, sendo a grande discussão nestes casos, se a manutenção do paciente com esta qualidade de vida é melhor ou pior do que a morte (PARANÁ, 2011 p.3).
\end{abstract}

Atualmente segundo Transplante (2004), existe um grande problema conceitual e prático quanto à aceitação de uma definição de morte humana com base na ausência de consciência detectável. Essa aceitação exigiria segundo a mesma instituição, uma mudança na definição da morte, do ponto de vista fisiológico para considerações psicológicas. Além disso, a consciência é por natureza subjetiva, sendo difícil sua exploração cognitiva. Diante disso e, segundo Escarlante (1996 apud Transplante, 2004) ante o substrato morfológico desconhecido que se baseia o conteúdo da consciência humana e não existindo um conjunto de critérios ou de confirmação do estado vegetativo persistente, torna-se muito difícil determinar sua irreversibilidade. 
Como se verificou, ambos os estados indicam que o paciente encontra-se em estágio não consciente, porém no primeiro não há possibilidade de que aquele volte a ter consciência, já no segundo apesar de remota, existe tal possibilidade. Para tanto, determina o Código de Ética Médica, que a conduta a ser seguida e a real situação deste paciente deve ser discutida amplamente com os familiares. Já o direito brasileiro não autoriza a facilitação da morte e nem obriga a utilização de recursos extraordinários para manutenção deste tipo de vida (PARANÁ, 2011). Assim, parece razoável, que diante da ausência de previsão legal, a conduta proposta pelo Código de Ética Médica apresenta-se como alternativa eficaz, desde que observado e preservado o princípio da dignidade humana e os demais princípios que possam ser feridos com a conduta.

\section{OS PRINCÍPIOS DA AUTONOMIA E DA DIGNIDA- DE HUMANA}

A Bioética como disciplina nasce principialista, pois no início dos anos 1970 quando ela surge como disciplina, pautava-se em alguns princípios norteadores (RAMOS, 2009). Já no final da década de 1970, início da década 1980, o estudo da Bioética pautou-se definitivamente em quatro princípios básicos enaltecedores da pessoa humana, sendo dois deles de caráter deontológico (não maleficência e justiça) e os demais, teleológico (beneficência e autonomia). Tais princípios foram consignados no Belmont Report, publicado em 1978 nos Estados Unidos (DINIZ, 2001).

A origem desses princípios e a reflexão ética, segundo Pessini e Barchifontaine (2000) estão relacionadas com a preocupação pública em relação ao controle social das pesquisas com seres humanos. Segundo os referidos autores, três casos mobilizaram a opinião pública americana e exigiram uma regulamentação ética: 1) em 1963, no Hospital Israelita de doenças crônicas de Nova lorque, foram injetadas células cancerosas vivas em pacientes idosos doentes; 2) entre as décadas de 1950 e 1970, no hospital estatal Willowbrok também em Nova lorque, foi injetada hepatite viral em crianças com Deficiência Mental; 3) e desde a década de 1940, descoberto somente em 1972, o caso de Tuskegee study no estado do Alabama, no qual foram deixadas sem tratamento quatrocentas pessoas sifilíticas para se pesquisar a história natural da doença, apesar da descoberta da penicilina em 1945.

Reagindo a esses ocorridos, em 1974, o Congresso dos Estados Unidos instituiu uma comissão com a finalidade de identificar os princípios básicos que deviam nortear experiências com seres humanos (The National Commission for the protection of humano of Biomedical end Behaviroal Research) que quatro anos depois publicou o Belmont Report (DALL'AGNOL, 2004).

Em 1978 foi publicado o livro Principles of Biomedical Ethics, de autoria de Beauchamp e Childress, que introduziu definitivamente os princípios na abordagem bioética. Tais autores consideram quatro princípios fundamentais aos estudos bioéticos: autonomia, não maleficência, beneficência e justiça (BEAUCHAMP; CHILDRESS, 1994). Para Diniz (2002) os princípios trazidos pelos referidos autores traduzem-se da seguinte maneira: o princípio autonomia requer que o profissional da saúde respeite a vontade do paciente; o princípio da beneficência solicita do agente a busca pelo interesse e bem estar do doente; em desdobramento da beneficência o princípio da não maleficência exige que não sejam causados danos intencionais aos pacientes; e por último, a justiça que deve ser aplicada de forma imparcial, pois os iguais devem ser tratados igualmente.

Assim, para a Bioética, os princípios são preceitos de conduta a serem seguidos pelos profissionais da saúde, não podendo os profissionais em nenhuma 
hipótese, distanciar suas práticas da conduta ética e dos princípios a ela elencados. Já na aplicação do

\subsection{PRINCÍPIO DA AUTONOMIA}

O princípio da autonomia requer, segundo Diniz (2001), que o profissional da saúde acate a vontade do paciente ou de quem o represente, levando em conta, seus valores morais e crenças religiosas. A mesma autora ainda reconhece que esse princípio estabelece o domínio do paciente sobre a própria vida (corpo e mente) e o respeito à sua intimidade, restringindo assim, intromissões alheias à pessoa que está sendo submetida ao tratamento. 0 genuíno ato médico não pode abstrair, na medida do possível, do conhecimento e da manifestação de interesse, a vontade do paciente ou de quem o represente (CLOTET, 2003).

Em sua obra On Liberty de 1859, que é uma das bases teóricas para o princípio da autonomia, Stuart Mill, define que o próprio bem do indivíduo, seja ele material ou moral, não constitui justificativa suficiente a ponto de que este deixe de ser ouvido, ou seja, não pode o indivíduo, legitimamente, ser compelido a fazer ou deixar de fazer algo (MILL, 2002). O paciente é quem deve se governar. Em termos simples segundo Dall'Agnol (2004), pode-se definir esse princípio da seguinte forma: respeite a autonomia da pessoa.

Contudo, existem limites ao exercício da autonomia, tal como a escolha sobre a vida ou a morte, ou seja, o indivíduo não pode dispor de sua vida, por mais irônico que isso possa parecer, a vida é um patrimônio do Estado, e este por ela deve zelar. (GIOSTRINI, 2006).

\subsection{PRINCÍPIO DA DIGNIDADE HUMANA}

Ao analisar o princípio da dignidade humana percebe-se que não é uma simples definição cartesiana, mas a ideia de um princípio “aberto”, de caráter uni-
Direito, os princípios bioéticos, completam os direitos fundamentais protetores da pessoa.

A autonomia surge como princípio, segundo Capilla (2007), a partir da democratização das relações humanas, entre outras, a relação médico e paciente, estendida além da clínica, que produziram no final do século XX uma crise no paternalismo médico, exigindo para tanto uma maior autonomia do paciente. O termo autonomia criado inicialmente para definir os autogovernos das cidades-estado helênicas, deriva, segundo Costa, Oselka e Garrafa (1998), do grego “auto” (próprio) e "nomos" (lei, regra), que pode ser entendido como autogoverno ou autodeterminação.

No entanto, a autonomia aqui pretendida é uma capacidade pessoal em relação à gestão de si mesmo. Essa autodeterminação deve ser resultado da capacidade do indivíduo de compreender a realidade a que está submetido, sendo que, aquele que tiver sua capacidade ou vontade reduzida deverá ser protegido (DI$\mathrm{NIZ}, 2001)$. Com esse entendimento do princípio da autonomia surgem os procedimentos práticos a serem tomados pelos profissionais da saúde: 1) a exigência do consentimento informado do paciente; 2) o procedimento a ser tomado, quando a pessoa for incompetente ou incapaz (PESSINI; BARCHIFONTAINE, 2000).

Portanto, a autonomia é a capacidade do indivíduo autogovernar-se e para exercê-la, ele deve estar em exercício pleno de suas capacidades intelectuais. Já nos casos de indivíduo incapaz ou temporariamente incapacitado, ele deverá ser protegido por quem tenha legitimidade de fazê-lo.

versal, indeterminado, plural em significados e mutante diante de novas realidades. Diante disso, para uma melhor compreensão desse princípio, procurar- 
-se-á descrevê-lo de forma linear e sem discussões terminológicas, clareando sua definição, sem deixar de reconhecer a amplitude deste princípio.

\section{No entendimento trazido por Kant (2004, p. 65):}

No reino dos fins, tudo tem ou um preço ou uma dignidade. Quando uma coisa tem preço, pode ser substituída por algo equivalente; por outro lado, a coisa que se acha acima de todo preço, e por isso não admite qualquer equivalência, compreende uma dignidade.

Segundo Alexandre de Moraes (2007, p. 66) trata-se de:

[...] um valor espiritual e moral inerente à pessoa, que se manifesta singularmente na autodeterminação consciente e responsável da própria vida e que traz consigo a pretensão ao respeito por parte das demais pessoas, constituindo-se em um mínimo invulnerável que todo o estatuto jurídico deve assegurar, de modo que apenas excepcionalmente possam ser feitas limitações [...]

Já a constituição desses valores espirituais, morais, insubstituíveis e inerentes à pessoa, não são inatos ao ser humano. A dignidade reside justamente no fato de que esse conceito está por se construir ao longo da vida, ou seja, a dignidade humana está em construção, sendo os momentos culturais e históricos vividos pela humanidade e pelo indivíduo que limitam os meandros desse princípio (MARTINS, 2005).

Portanto, a dignidade é valor insubstituível que está presente na autodeterminação consciente da pessoa, em exercer os seus valores morais e espirituais, respeitando e sendo respeitada. É ainda, um princípio mutável capaz de acompanhar o aprendizado e a evolução tanto do indivíduo particular quanto da humanidade.

Por sua capacidade de mutabilidade na preservação da pessoa, a dignidade foi inserida na Constituição Brasileira, não somente como um direito, mas sim como princípio fundamental da República:
A dignidade da pessoa humana constitui fundamento de nosso Estado Democrático de Direito (artigo 1 $^{\circ}$ inciso III, da Constituição de 1988). [...] O constituinte de 1988 preferiu não incluir a dignidade da pessoa humana no rol dos direitos e garantias fundamentais, guindando-a à condição de princípio (e valor) fundamental (SARLET, 2010. p 72-77).

Nery Júnior e Nery ressaltam a importância desse princípio:

[...] reflete-se em princípios gerais de direito quando informam seus elementos e privilegiam a realidade fundamental do fenômeno jurídico que é a consideração primordial e fundamental de que o homem é sujeito de direito e, nunca, objeto de direito (NERY JÚNIOR. NERY, 2006. p. 118).

A dignidade humana é precondição da legitimação da República como forma de domínio, mas não se trata aqui de um dado fascista, invariável e abstrato. A dimensão essencial e autônoma da dignidade humana articula-se com a liberdade e a orientação da vida segundo o projeto espiritual de cada pessoa, o que aponta para necessidade, não distante da exigência de um constante antropológico, buscando uma abertura às novas exigências da própria pessoa humana (CANOTILHO; MOREIRA, 2007). A dignidade da pessoa humana forma um impedimento absoluto e instransponível, inclusive para os atores estatais, blindando a individualidade e autonomia da pessoa contra qualquer tipo de interferência por parte do Estado e de terceiros, de tal sorte a assegurar o papel do ser humano como sujeito de direitos (SARLET, 2010).

Obviamente, un concepto así construido no permite definiciones cartesianas, claras y distintas. Pero ya Ludwig Wittgenstein se preguntaba: ¿"Será siempre ventajoso cambiar un retrato poco claro por otro bien nítido? ¿No será el retrato poco nítido exactamente lo que necesitamos?”. Parece que sí. Es de este concepto de dignidad que todavía tenemos necesidad. Un concepto que, por ser más rico en sedimentaciones éticas y soluciones morales, aun en sus contradicciones, constituye una reserva insustituible de estratégias de valorización del ser humano en sus más diferentes contextos (PYRRHO; CORNELLI; GARRAFA, 2009. p. 65-69). 
Assim, brevemente definida a dignidade humana, aqui entendida como valor inerente à pessoa, da qual não poderá ser amputada sem seu consentimento, mutável diante da realidade histórico-cultural da humanidade. Deste modo, tem-se como princípio diante dos avanços científicos atuais e futuros, constando ou não no rol dos princípios bioéticos, que ao bioeticista, cabe o dever de ter a dignidade humana como paradigma, pois é fundamento do Estado Democrático de Direito, sendo o valor que prevalecerá diante de qualquer avanço científico e tecnológico (DINIZ, 2002).

\subsection{PRINCÍPIO DA AUTONOMIA REPRODUTIVA}

Os direitos reprodutivos, assim como os sexuais, são construções recentes, frutos de reflexões teóricas sobre os direitos individuais e coletivos, dentro de uma concepção dos Direitos Humanos e com fundamental vinculação com a autonomia, que requer o direito fundamental do exercício de liberdade (SOUZA; ALVARENGA, 2007). Portando, para entender o princípio da liberdade reprodutiva, faz-se necessário compreender inicialmente, o princípio da liberdade.

A liberdade é um direito que garante a não ingerência do Estado na esfera de liberdades dos cidadãos, sendo nesse sentido reconhecida como "direito negativo", pois em face do Estado ele implica um direito de abstenção de impedimentos ou obstáculos (CANOTILHO; MOREIRA, 2007). Segundo Alexy (2007) o princípio da liberdade negativa pode se basear, em toda sua amplitude, no princípio da dignidade humana. Sendo que essas liberdades em alguns casos, desde que existam razões suficientes, podem sofrer restrições caso atinjam direitos de terceiros ou interesses coletivos (ALEXY, 2007). A liberdade como um direito negativo ao Estado, ao cidadão, é positiva e se refere ao respeito do exercício de um anseio autodeterminado e não heterodeterminado, 0 livre-arbítrio do cidadão (BOBBIO, 1997).

A liberdade contemplada no rol dos direitos autodeterminados, ou seja, aqueles em que o próprio cidadão determina seus atos, são protetores da liberdade reprodutiva. Essa proteção foi confirmada na
Destarte, a dignidade humana, como dito no início dessa seção é um princípio "aberto" e isso requer de quem a interprete, um apanhado geral dos valores sociais e morais do momento histórico em que se vive e dos valores inerentes a pessoa ou das pessoas atingidas. Ausentar-se dessa análise não fere só um princípio, mas a toda sociedade, que providenciou nesse princípio a proteção de seu bem mais caro.

Conferência Internacional de Beijing em 1995, que reconheceu o direito básico de todos os casais e indivíduos, a decidirem livre e responsavelmente sobre o número de filhos, espaçamentos dos nascimentos e o intervalo entre eles, bem como, dispor da informação e dos meios para tanto e a obter o mais elevado nível de saúde sexual e reprodutiva (DINIZ, 2002). Configura-se, assim, uma oposição às teorias conceptivas, que falsamente diagnosticavam o crescimento populacional como a causa dos problemas sociais, e respeita-se a liberdade de escolha dos indivíduos (PESSINI; BARCHIFONTAINE, 2000).

Ao contemplar esse entendimento a Constituição Brasileira trás a seguinte redação quanto à proteção dos direitos reprodutivos (art. 226, $\$ 7^{\circ}$ ):

\section{Fundado nos princípios da dignidade da pessoa hu- mana e da paternidade responsável, o planejamento familiar é livre decisão do casal, competindo ao Esta- do propiciar recursos educacionais e científicos para o exercício desse direito, vedada qualquer forma co- ercitiva por parte de instituições oficiais ou privadas (BRASIL, 2012-B)}

A Lei 9.263/1996 regulamenta o parágrafo $7^{\circ}$ do art. 226 "O planejamento familiar é parte integrante do conjunto de ações de atenção à mulher, ao homem ou ao casal, dentro de uma visão de atendimento global e integral à saúde", advertindo que a universalidade dos 
direitos sexuais e reprodutivos são aplicáveis indistintamente a homens e mulheres (BRASIL, 2012-C).

Assim todos têm direito à concepção e à descendência, podendo exercê-lo por via de ato sexual ou fertilização assistida, em caso de infertilidade [...] desde que isso não coloque a vida do paciente e do próprio descendente em risco (DINIZ, 2002 p. 137).

Ressalva ainda a autora, que essa liberdade não exclui a maternidade ou a paternidade das devidas responsabilidades, de forma que sejam bem compreendidas e assumidas.

Deste modo é direito do indivíduo, sem a interferência do Estado, decidir sobre sua família e descendência, pois é a família uma entidade autônoma, gerida por seus membros, que serão responsáveis por ela, cabendo ao Estado o dever de assegurar as condições para o bem estar de todos.

\section{COLISÃO DE PRINĆIPIOS E DIREITOS FUNDA- MENTAIS}

A divisão do estudo, em dois momentos distintos, permitiu até aqui, a compreensão individual dos procedimentos da área da Biomedicina, assim como dos princípios bioéticos e constitucionais, ambos, envolvidos na discussão da reprodução assistida em paciente comatoso masculino. Procurar-se-á neste capítulo analisar três procedimentos possíveis de reprodução assistida em paciente comatoso em face dos princípios protetores da pessoa humana.

Assim, faz-se necessário descrever cada uma das três possíveis situações que são: a coleta do sêmen do paciente comatoso, doação prévia do sêmen com autorização do doador, doação prévia do sêmen sem autorização e confrontá-las aos princípios bioéticos e constitucionais.

Temos então, um homem em estado comatoso, estado esse que é resultado da falência dos mecanismos normais de manutenção da consciência (PARANÁ, 2000). Diante dessa situação, sua esposa ou companheira, decide utilizar seu material genético no intuito de gerar filiação de ambos.

Na primeira hipótese possível, o paciente comatoso não realizou doação prévia de seu material genético, no entanto, sua esposa deseja coletá-lo para realizar o procedimento de reprodução assistida.

Diante dessa situação Telöken et al (2002) são categóricos em afirmar que apesar de possível e já se tenha realizado tal procedimento, seria inaceitável a coleta de sêmen em casos de coma ou morte do indivíduo. Frente às circunstâncias, parece correta a opinião dos autores, uma vez que, ausência de doação prévia, levanta séria dúvida quanto ao interesse do paciente em ter seu sêmen utilizado, sendo que, não autorizou tal procedimento e não há manifestação sua no sentido de que aprovaria esse tipo de conduta. Porém, pode o paciente anteriormente ao coma ter se manifestado, informalmente, e isso pode ser alegado por seus parentes ou amigos próximos, no sentido de permitir tal procedimento se necessário, o que excluiria a ausência de sua manifestação.

No entanto, o paciente, quanto à sua manifestação, não chegou a exteriorizá-la de modo a tornar indubitável tal intenção, ou seja, ele não contribuiu para autorizar a realização de tal procedimento. É, portanto, incoerente a realização da coleta do sêmen do paciente que se encontra em estado de coma irreversível, tendo em vista um excesso de intervenção, por parte de quem 
o faça, na autonomia e também na dignidade dele, uma vez que não exteriorizou sua vontade.

$\mathrm{Na}$ segunda hipótese, o homem previamente doador de espermatozoides congelados em laboratório especializado em fertilização assistida ou em armazenamento de material genético, deixa por escrito autorização para sua utilização caso ele esteja impossibilitado de fazê-lo.

Quanto aos procedimentos de reprodução assistida em paciente em estado comatoso, o legislativo brasileiro ainda não se pronunciou, no entanto, o Conselho Federal de Medicina redigiu Resolução no seguinte sentido:

No momento da criopreservação, os cônjuges ou companheiros devem expressar sua vontade, por escrito, quanto ao destino que será dado aos pré-embriões criopreservados em caso de divórcio, doenças graves ou falecimento de um deles ou de ambos, e quando desejam doá-los (BRASIL, 2012-A).

Portanto, existindo manifestação do paciente no sentido de que se utilize seu material genético, quando ele não possa autorizar, nada se interpõe à realização do procedimento, uma vez que, está se respeitando a vontade do pretendido pai.

Um pouco menos pacífica é a terceira hipótese, na qual a esposa ou companheira deseja gerar descendente, sendo que apesar do pretendido pai ter deixado sêmen previamente congelado, não deixou autorização quanto à sua utilização.

Como já dito, o legislativo brasileiro ainda não se pronunciou quanto a esse assunto, porém, o Conselho Federal de Medicina redigiu a Resolução 1.957/2010, prevendo os procedimentos a serem tomados em casos extremos, ausente expressa autorização, não sendo no entendimento desse ente, permitida a utilização do material genético doado.

No entanto, é importante ressaltar, quanto à tal Resolução, que a Constituição Federal prevê a criação de regulamentos por parte dos órgãos do Executivo, do qual fazem parte o Conselho Federal de Medicina e seus Conselhos Regionais, uma vez que o cumprimento de determinadas leis pressupõe interferência de tais órgãos. No entanto, a regra do art. $68, \$ 1^{\circ}$, II do mesmo dispositivo, veda de forma taxativa tal delegação quando tratar, entre outros, de matéria referente aos direitos individuais (MELLO, 2011). Ou seja, inexiste suporte jurídico a tal determinação do Conselho Federal de Medicina. Deste modo, nada impede que a autorização para tal procedimento de reprodução assistida, seja discutida judicialmente em virtude da ausência de legítima previsão legislativa.

Como visto em ponto anterior, a Constituição, segundo Diniz (2002), garante a homens e mulheres, casal ou individualmente decidirem livremente sobre a concepção de seus filhos. E em que pese entender-se, que a referida autora é contrária a tal procedimento, uma vez que não aprova a modalidade de reprodução assistida, tal previsão legal repassa à pessoa e não ao Estado a pretensão de decidir sobre sua descendência, sendo, portanto, diante do princípio da liberdade reprodutiva, livre a esposa para buscar judicialmente seu direito.

Entendendo-se que dignidade humana, que segundo Moraes (2007), se refere a valores sociais, morais e espirituais, o indivíduo carrega durante sua vida. Sendo que as crenças e pretensões compartilhadas com outras pessoas também fazem parte da dignidade da pessoa (MARTINS, 2005). A realização de atos contrários às concepções particulares e às concepções que a pessoa compartilha com a sociedade, macularia a dignidade do paciente. No que diz respeito ao procedimento referido, não parece ocorrer tal violação, uma vez que era pretensão do paciente gerar descendência, caso contrário não haveria coletado material genético com tal intenção. Assim, o princípio da dignidade não impede que se utilize o sêmen do doador comatoso.

Talvez o que mais suscite dúvida, quanto à possibilidade de utilização do material genético do paciente, 
por não haver possibilidade de manifestação de sua vontade, diga respeito ao princípio da autonomia do paciente. Quanto à incapacidade do sujeito, quando inconsciente e não mais respondendo por si, deve-se por ele intervir, afirmam Pessini e Barchifontaine (2000).

Portanto, sendo a pessoa diversa, responsável pela tomada de decisões que recaem sobre o interesse do paciente, terá a esposa ou companheira responsabilidade pelo paciente em estado comatoso. Tal transferência, no entanto, não autoriza que essa utilize material genético do incapacitado, pois a substituição da autonomia, segundo Diniz (2002) é quanto à proteção, é por isso, limitada a decisões essenciais à proteção da vida ou dignidade do incapacitado. Tal autorização se torna incompatível com o mero arbítrio de quem quer que seja.

É relevante mencionar que recentemente foi concedida pela $13^{a}$ Vara Cível da Comarca de Curitiba, liminar favorável à esposa, que perdeu o marido vítima de câncer, para tentar engravidar. No caso em questão, a esposa ao procurar o laboratório no qual o esperma estava armazenado, fora informada de que não poderia realizar tal procedimento, uma vez que seu marido não havia deixado consentimento prévio liberando o uso do material. No entanto, no caso ora analisado, o
Judiciário acolheu o argumento da autora, de que era possível presumir a vontade do marido baseando-se em depoimentos de amigos e familiares (JORNAL DA ORDEM, 2010).

Todavia, não seria correto fazer analogia entre a situação do paciente em coma irreversível e o indivíduo já falecido, uma vez que o primeiro não tem consciência detectável, ou seja, está legalmente vivo (ROSENBERG, 2009), e o segundo já declarado morto (JAMA, 1968). Entretanto, o argumento trazido pela autora, quanto à presunção do consentimento, pode servir a ambos os casos, uma vez que o que impede a realização do procedimento é, como se viu, a ausência do consentimento prévio do doador.

Importante lembrar, que na primeira hipótese, falou-se que o consentimento não poderia ser presumido diante das manifestações informais do paciente, no entanto, essa não se confunde com a terceira hipótese, uma vez que nesse caso houve contribuição do paciente para que se realizasse o procedimento de reprodução assistida utilizando seu sêmen congelado. Nesse caso, é possível a realização do procedimento mesmo sem ter o doador deixado autorização por escrito.

\section{CONCLUSÃO}

O progresso trazido pelas técnicas de reprodução assistida trouxe consigo novas possibilidades, e, sobretudo, levantou novas discussões de natureza ética. Nesse contexto, enquadra-se, a reprodução em paciente comatoso masculino que levanta vários questionamentos quanto à possibilidade de sua realização.

Sabe-se que com a utilização da técnica de fertilização in vitro pode a esposa ou companheira gerar descendente, havendo a coleta de sêmen antes ou durante o estado de coma, estado esse que impossibilita ao paciente responder a estímulos ou apresentar normal consciência. Deste modo, um indivíduo, diante da técnica in vitro, pode ter seu material genético utilizado na geração de um novo ser, mas para esse procedimento não será capaz de dar sua concordância, salvo no caso em que deixou expressa essa vontade.

Foram demonstradas três possíveis situações em que se pode utilizar da técnica in vitro para gerar nova vida humana, nas quais o doador do sêmen não estará consciente no momento em que o procedimento de reprodução assistida será realizado. 
A primeira hipótese trata da retirada do sêmen do doador estando ele em coma. Essa possibilidade, no tocante aos princípios constitucionais, parece ser demasiadamente invasiva ao paciente, uma vez que não haveria doação, mas uma expropriação do sêmen do indivíduo, pois esse em nada contribuiu para autorizar o uso de seu material genético. Já a segunda hipótese, estabelece a situação de um doador, o qual coletou o sêmen para ser utilizado, e era favorável à sua utilização, uma vez que autorizou por escrito tal determinação. Na terceira hipótese, o paciente, ao contrário da primeira, é um doador, porém diferente da segunda, uma vez que não deixou por escrito o que fazer com seu material

\section{REFERÊNCIAS}

A DEFINITION OF IRREVERSIBLE COMA. Report of the Ad Hoc Committee of the Harvard Medical School to Examine the Definition of Brain Death. JAMA .1968 Aug 5; 205(6):85-88. Disponível em: <http://www. hods.org/english/h-issues/documents/ ADe- finitionoflrreversibleComa-JAMA1968.pdf>. Acesso em: 15 nov. 2011.

ALEXY, Robert. Teoria dos direitos fundamentais. 5. ed. São Paulo; Malheiros editores, 2007. 669 p.

BONAVIDES, Paulo. Curso de direito constitucional. 18. ed. São Paulo: Malheiros Editores,2006. 807 p.

BEAUCHAMP TL, CHILDRESS JF. Principles of Bioemdical Ethics. 4ed. New York: Oxford, 1994:100-103.

BOBBIO, N. Igualdade e liberdade. Rio de Janeiro: Ediouro, 1997

BRASIL. Conselho Federal de Medicina. RESOLUÇÃo CFM n 1.957/10. Disponível em: < http://www.portalmedico.org.br/resolucoes/CFM/2010/1957_2010. htm> Acesso em: mar. 2012-A. genético caso estivesse impossibilitado. A solução encontrada para esta circunstância seria comprovar, ouvindo pessoas próximas ao doador e diante de suas atitudes, se é esse o desejo dele se caso manifestar-se fosse possível.

Assim, portanto, haveria de ser negativa a solicitação de realização do procedimento de reprodução assistida em paciente comatoso masculino, quando houver necessidade de coleta de material genético do paciente. Já nos casos em que haja prévia doação, tal solicitação poderá ser concedida, uma vez haja autorização por escrito ou, pelo menos como comprovar ser esse o desejo do doador.

BRASIL, Constituição da República Federativa do Brasil de 1988. Disponível em: <http://www.planalto. gov.br/ccivil_03/constituicao/constitui\%C3\%A7ao. htm>. Acesso em: mar. 2012-B.

BRASIL. LEI No 9.263, DE 12 DE JANEIRO DE 1996. . Disponível em:http://www.planalto.gov.br/ccivil_03/ leis/L9263.htm . Acesso em: fev. 2012-C.

CANOTILHO, J.J. Gomes; MOREIRA, Vital. Constituição da república portuguesa anotada. 1. ed. São Paulo; Revista dos tribunais; Coimbra, PT: Coimbra editora, 2007. 1123 p.

CAPILLA, Diego José García. El nacimiento de la bioética. Madrid: Biblioteca Nueva, 2007. 238 p.

COSTA, Sergio Ibiapina Ferreira; OSELKA, Gabriel e GARRAFA, Volnei, coord. Iniciação à Bioética. Brasília: Conselho Federal de Medicina, 1998. Disponível em: http://www.portalmedico.org.br/novoportal/index5.asp\#. Acessado em 30/09/2011. 
CLOTET, Joaquim. Bioética: uma aproximação. Porto Alegre: EDIPUCRS, 2003. 246 p.

DALL'AGNOL, Darlei. Bioética. Rio de Janeiro: DP\&A, 2004. 197 p.

DINIZ, Maria Helena. 0 Estado Atual do Biodireito: São Paulo: Saraiva, 2001. 791 p.

DINIZ, Maria Helena. O Estado Atual do Biodireito: 2. ed.São Paulo: Saraiva, 2002. 839 p.

DONADIO, Nilson; DONADIO, Nilka Fernandes. Reprodução humana laboraterialmente assistida. In: DONADIO, Nilson; LOPES, Joaquim Roberto Costa; MELO, Nilson Roberto de. Reprodução humana II: infertilidade, aticoncepção e reprodução assistida. São Paulo: Organon, 1997. Cap. , p. 137-172.

GIOSTRINI, Hildegard Taggesell. A morte, o morrer, a doação de órgãos e a dignidade humana. In: CORRÊA, Elídia Aparecida de Andrade; GIACOIA, Gilberto; CONRADO, Marcelo. Biodireito e a dignidade humana: dialogo entre as ciências do direito (coords). Curitiba: Juruá, 2006. 336 p.

HRYNIEWICZ, Severo; SAUWEN, Regina Fiuza. 0 Direito "in vitro" da bioética ao biodireito. 3. ed. Rio de Janeiro: Lumen Juris, 2008. 254 p.

JORNAL DA ORDEM (Porto Alegre) (Ed.). Justiça do PR autoriza mulher a usar sêmen de marido morto. Disponível em: <http://www.jornaldaordem.com.br/noticia_ler.php?id=17809>. Acesso em: 10 maio 2012.

KANT Immanuel. Fundamentação da metafísica dos costumes e outros escritos. Tradução de Leopoldo Holzbach, São Paulo: Martin Claret, 2004.

LOPES, Joaquim Roberto Costa et al. Inseminação intra-uterina. In: DONADIO, Nilson et al. Reprodução humana II: infertilidade, aticoncepção e reprodução assistida. São Paulo: Organon, 1997. Cap. , p. 123-135.
MACHADO, Maria Helena. Reprodução humana assistida: Controvérsias éticas e jurídicas. Curitiba: Juruá, 2003. 156 p.

MARTINS, Flademir Jerônimo Belinati. Dignidade da pessoa humana: princípio constitucional fundamental. 1. ed. Curitiba: Juruá, 2005. 141 p.

MELLO, Celso Antônio Bandeira de. Curso de direito administrativo. 28. ed. São Paulo: Malheiros, 2011. 1127 p.

MILL, Jonh Stuart. On liberty. Mineola/USA; Dover thrift editions, 2002

MORAES, Alexandre de. Constituição do Brasil interpretada e legislação constitucional. 7. ed. São Paulo: Atlas, 2007. 2976 p.

MUNIZ, E. C. S. et. al. Utilização da escala de coma de Glasgow e escala de Jouvet para avaliação do nível de consciência. Rev. Esc. Enf. USP, 31, n.2, p. $287-$ 303, ago. 1997.

MUÑOZ, Daniel Romero; FORTES, Paulo Antonio Carvalhos. O Princípio da Autonomia e o Consentimento Livre e Esclarecido. In: COSTA, Sergio Ibiapina Ferreira; OSELKA, Gabriel; GARRAFA, Volnei.Iniciação à bioética. Brasilia: Conselho Federal de Medicina, 1998. p. 53-70.

NERY JUNIOR, Nelson; NERY, Rosa Maria de Andrade. Constituição Federal comentada e legislação constitucional. São Paulo: Revista dos Tribunais, 2006. 911 p.

PARANÁ. Conselho Regional de Medicina. Parecer no 1243/2000. Disponível em: http://www. portalmedico.org.br/pareceres/CRMPR/pareceres/2000/1243_2000.htm. Acesso em: 30 set. 2011.

PESSINI, Léo; BARCHIFONTAINE, Christian de Paul de. Problemas atuais de biodireito. 5. Ed. São Paulo: Loyola, 2000. 527 p. 
PYRRHO, Monique; CORNELLI, Gabriele; GARRAFA, Volnei. DIGNIDAD HUMANA: RECONOCIMIENTO Y OPERACIONALIZACIÓN DEL CONCEPTO. Acta bioeth., Santiago, v. 15, n. 1, 2009. Disponível em <http://www.scielo.cl/scielo.php?Script =sci_ arttext\&pid=S1726-569X2009000100008\&lng=pt\&nr m=iso>. acesso em 10 dez. 2011.

RAMOS, Dalton Luiz de Paula (Org.). Bioética: pessoa e vida. São Caetano do Sul: Difusão Editora, 2009. 374 p.

ROSENBERG, N. Reger. Consciousness, Coma, and Brain Death-2009. The Journal Of The American Medical Association, Jama, p. 1172-1174. 18 Mar. 2009. Disponível em: <http://jama.amaassn.org/content/301/11/1172. full.pdf+html>. Acesso em: 30 nov. 2011.

SÁ, Maria de Fátima Freire de; NAVES, Bruno Torquato de Oliveira. Manual de biodireito. Belo Horizonte: Del Rey, 2009. 364 p.

SAMRSLA, Mônica et al. (Ed.). Expectativa de mulheres à reprodução assistida em hospital público do DF Estudo Bioético. Rev Assoc Med Bras, Brasilia, v. 1, n. 53, p.47-52, 2007. Disponível em: <http://www.scielo. br/pdf/ramb/v53n1/19.pdf>. Acesso em: 03 out. 2011. SARLET, Ingo Wolfgang. Dignidade da Pessoa Humana e Direitos Fundamentais. 10 ed. Porto Alegre: Livraria do Advogado, 2010.

SILVA, Reinaldo Pereira e. Introdução ao biodireito: Investigação político-jurídicas sobre o estatuto da concepção humana. São Paulo: Ltr, 2002. 391 p.
SOUZA, Raquel; ALVARENGA, Augusta Thereza de. Direitos sexuais, direitos reprodutivos: concepções de mulheres negras e brancas sobre liberdade. Saude soc. 2007, vol.16, n.2, pp. 125-132. ISSN 0104-1290. Disponível em: <http://dx.doi.org/10.1590/S0104$12902007000200012>$. Acesso em 13 mar. 2012.

TELÖKEN, Cláudio et al. Bioética e reprodução assistida. Amrigs, Porto Alegre, v. 3,4, n. 46, p.100104, jul.-dez. 2002. Disponível em: <http://www. amrigs.com.br/revista/46-03/Bio\%E9tica\%20e\%20 reprodu\%E7\%E30\%20assistida.pdf>. Acesso em: 10 maio 2012.

TRASPLANTE, Grupo De Estudios Sobre Muerte Encefálica De Las Sociedades Chilenas De Nefrología Y De (Org.). Muerte encefálica, bioética y trasplante de órganos. Rev Méd Chile: Etica Médica, Santiago, v. 132, n. , p.109-118, 2004.

WIJDICKS, Eelco F.M.The diagnosis of brain death. N Engl J Med. 2001; 344: 1215-21. Disponível em: <http://hcnet.usp.br/adm/dc/opo/artigos/Revissao\%20da\% 20morte\%20encefalica.pdf>. Acesso em: 15 nov. 2011.
Recebido em: 2 de outubro de 2012 Avaliado em: 27 de dezembro de 2012 Aceito em: 28 de janeiro 2013
I Acadêmico do Curso de Graduação em Direito da Universidade do Extremo Sul Catarinense. Pesquisador bolsista do Programa Institucional de Bolsas de Iniciação Científica. Graduado em Geografia Licenciatura e em Geografia Bacharelado - Universidade do Extremo Sul Catarinense. Professor do Magistério Público Estadual de Santa Catarina. E-mail: tiagomafralima@ hotmail.com

II Graduado em Direito pela Universidade Federal do Rio Grande do Sul. Mestre em Ciências Criminais pela Pontifícia Universidade Católica do Rio Grande do Sul. Professor universitário, pesquisador do Núcleo de Pesquisa em Direitos Humanos e Cidadania da Universidade do Extremo Sul Catarinense.E-mail: phconti@ibest.com.br 